\title{
Role of Laparoscopic-Assisted Gastric Per-oral Endoscopic Pyloromyotomy in Refractory Gastroparesis
}

\author{
Jacob Trygve Lambdin ${ }^{1} \cdot$ Steven Zeddun ${ }^{1} \cdot$ Marie L. Borum ${ }^{1}$ \\ Received: 6 February 2018 / Accepted: 16 February 2018 / Published online: 3 March 2018 \\ ○) Springer Science+Business Media, LLC, part of Springer Nature 2018
}

We have read with interest the article authored by Navas et al., entitled "Gastroparesis: Medical and Therapeutic Advances" (1) and would like to congratulate the authors on their thoughtful and comprehensive review of the topic. Respectfully, we would like to offer additional perspective on some of the complexities pertaining to the contribution of gastric per-oral endoscopic myotomy (G-POEM) to the management of gastroparesis. We agree with the authors that patients with a pyloric origin of their disease must be identified prior to attempting G-POEM in order to ensure optimal outcomes. The two most common means of identifying pyloric pathology are via trial of transpyloric stent placement and submucosal pyloric botulinum toxin injection. These temporary interventions may predict the success of subsequent G-POEM by localizing the source of the patient's pathology, at least in part, to the pylorus. If a patient's symptoms improve with one of these measures, it may be appropriate to then proceed with a definitive endoscopic intervention. There are multiple variations of G-POEM that may be considered, including unguided G-POEM, fluoroscopic-guided G-POEM, and laparoscopicassisted G-POEM.

We report a case of successful laparoscopic-assisted G-POEM in a patient with refractory diabetic gastroparesis. The patient is a 30 -year-old man with a 10-month history of refractory diabetic gastroparesis requiring total parenteral nutrition. Since he had minimal response to prokinetic agents, injection of botulinum toxin into the pylorus was performed, which decreased his vomiting. The G-POEM was subsequently performed using laparoscopic assistance that confirmed the exact location and orientation of the submucosal tunnel enabling precisely targeted myotomy. Laparoscopic assistance can provide the proper exposure and angulation of the distal stomach. The procedure was successful and free of complications. The patient was discharged to home on postoperative day 6 and consuming a normal diet. Similar to the authors, we believe that G-POEM holds great promise to improve the lives of those suffering from gastroparesis, appreciating that G-POEM is still an evolving technique. The authors have noted that the submucosal injection of botulinum toxin, which may improve symptoms temporarily, can potentially scar the submucosal space technically complicating the procedure (2). A guided technique, via fluoroscopy or laparoscopy, may be more appropriate for patients in whom a difficult submucosal dissection is anticipated, such as those with anatomical distortions or a history of local botulinum toxin injection. Furthermore, the expertise and experience of the provider must also be taken into account. Further studies are necessary to elucidate which patients will benefit most from each of the various G-POEM approaches.

Marie L. Borum

mborum@mfa.gwu.edu

1 Division of Gastroenterology and Liver Diseases, George Washington University Medical Center, 2150 Pennsylvania Avenue, NW, Suite 3-405, Washington, DC 20037, USA 